\title{
Condições de trabalho de auxiliares de enfermagem de um instituto de ortopedia e traumatologia de um hospital público de São Paulo
}

\author{
Mariana Brandão Lourenço Gonçalves ${ }^{2}$ e Frida Marina Fischer ${ }^{3}$
}

\begin{abstract}
Este estudo refere-se à continuação de outro sobre envelhecimento e trabalho (Gonçalves, Fischer, Lombardi Jr. Ë Ferreira, 2001) em um hospital público de São Paulo, Brasil. Foi observada diminuição da capacidade de trabalho entre trabalhadores de enfermagem em função do trabalho em turnos e das atividades físicas por eles realizadas. Objetivo: Avaliar, de forma abrangente, postos de trabalho de auxiliares de enfermagem durante os turnos diários de 12 horas, nos períodos diurno e noturno. São descritos e comparados alguns problemas relacionados à organização do trabalho nos diferentes turnos e setores. As observações foram realizadas em quatro setores do mesmo hospital. O método utilizado para coleta de dados foi baseado na técnica de análise ergonômica do trabalho segundo proposta de Rohmert e Landau (1983). Apesar do turno diurno apresentar maior carga de trabalho, o número reduzido de auxiliares de enfermagem escalados para o turno noturno faz com que a carga de trabalho por pessoa seja grande também à noite. É importante adequar o número de pessoas escaladas em cada turno e setor às demandas do hospital e dos pacientes com o objetivo de superar as dificuldades das tarefas e promover melhores condições de trabalho aos auxiliares de enfermagem.
\end{abstract}

Palavras-chave: trabalhadores em turnos, auxiliares de enfermagem, análise ergonômica do trabalho, condições de trabalho.

\section{Introdução}

$\mathrm{O}$ trabalho hospitalar vem sendo motivo de preocupação devido aos riscos que o ambiente oferece e aos aspectos penosos das atividades desenvolvidas. Além disso, destacam-se as alterações biológicas, cognitivas e sociais causadas pelo trabalho noturno (Estryn-Behar \& Bonnet, 1992). Particularmente, as alterações no ciclo vigília-sono, decorrentes da organização do trabalho em turnos em hospitais e outros serviços de saúde, podem levar a importantes débitos crônicos de sono, os quais poderão prejudicar o atendimento a pacientes e contribuir para agravar a fadiga e o mal-estar. A necessidade de trabalhar em horários coincidentes com o fim-de-semana tradicional, feriados, durante os períodos vespertino e noturno afeta negativamente as relações sociais (Niedhammer, Lert \& Marne, 1994).

Convém também lembrar que os esforços físicos decorrentes das longas distâncias percorridas durante a jornada de trabalho, as complexas e difíceis interações entre pacientes e o corpo de enfermagem geram problemas de saúde, de sono, dificuldades para a realização do

\footnotetext{
${ }^{1}$ Agradecimento: CNPq - Bolsa de Iniciação Científica 107250/99-3 e Projeto Integrado 521981/96-4.

${ }^{2}$ Psicóloga formada pelo Instituto de Psicologia da Universidade de São Paulo, acompanhante terapêutica, ex-bolsista PIBIC do Departamento de Saúde Ambiental da Faculdade de Saúde Pública da Universidade de São Paulo.

${ }^{3}$ Docente do Departamento de Saúde Ambiental da Faculdade de Saúde Pública da Universidade de São Paulo.
} 
trabalho e fazem parte do leque de estressores relacionados a riscos ocupacionais no trabalho de enfermagem (Fischer \& Bellusci, 2000; Villatte, Gadbois, Bourne \& Laurent, 1993).

Condições físicas e ambientais do local de trabalho, organização do trabalho, diferenças individuais não atendidas nos processos de produção, variáveis de ordem psicossocial dos ambientes de trabalho e de ordem individual - tanto psicológica, quanto relativa aos hábitos e atividades da vida extra-ocupacional - contribuem para o desenvolvimento de doenças ocupacionais ou para o agravamento de sintomas ou doenças pré-existentes. Esse conjunto de variáveis aponta para a necessidade de mais estudos nessa área e possíveis intervenções que conciliem as necessidades das empresas com o bem-estar dos trabalhadores.

Os turnos de 12 horas de trabalho contínuo, seguidos de 36 horas de descanso, exigem esforços físicos e mentais intensos em profissionais da área da saúde. Além disso, para trabalhadores de turnos noturnos, os ritmos biológicos e sociais sofrem alterações significativas (Fischer, Teixeira, Borges, Gonçalves \& Ferreira, 2002), de forma que o organismo deve se adaptar às condições oferecidas pelo trabalho; o trabalhador passa a ter privação e perturbações do seu sono, o que pode gerar estresses físico e mental, diminuindo sua capacidade para o trabalho.

Marziale e Carvalho (1998), em estudo numa unidade de internação de um hospital em São Paulo, consideraram viável a adoção de um princípio de medidas médias para análise da adequação dos mobiliários existentes no ambiente de trabalho estudado, visto que há uma significativa rotatividade da força de trabalho no serviço de enfermagem e uma amplitude das variações das medidas antropométricas encontradas. A inadequação da altura das superfícies induz os trabalhadores a curvarem sua coluna vertebral ao executarem suas atividades no local de trabalho. Essa situação pode ser considerada um fator de risco para o aparecimento de lombalgias, problema de saúde muito freqüente entre os trabalhadores de enfermagem.

Vários estudos vêm sendo realizados a fim de orientar o trabalhador a posicionar seu corpo corretamente durante a execução de suas atividades laborais. Segundo os ergonomistas, isto não é suficiente, pois existe a necessidade de modificações também no trabalho para que o trabalhador possa assumir postura corporal adequada e confortável, levando-se em conta, ainda, a variação de movimentação e a permanência de tempo em cada posição (Marziale \& Carvalho, 1998). Segundo Wisner (1987), citado por Marziale e Carvalho (1998), o trabalhador se esforça para responder às exigências da tarefa e das condições de inadequação na estrutura dimensionada do posto de trabalho, mobiliário e iluminação, frente às suas características antropométricas.

Um estudo anterior realizado em 1999 (Gonçalves, Fischer, Lombardi Jr. \& Ferreira, 2001) entre auxiliares e atendentes de enfermagem de um hospital público de São Paulo (com a utilização do Índice de Capacidade para o Trabalho, ICT), revelou que lesões nas costas, nos braços, nas mãos e dores nas costas que se irradiam para as pernas são as principais ocorrências relatadas tendo diagnóstico médico e foram provavelmente conseqüências dos fatores de risco anteriormente citados.

Este estudo teve em vista dar continuidade ao trabalho de Gonçalves et al. (2001), e utilizou como instrumento a Análise Ergonômica do Trabalho (Rohmert \& Landau, 1983) para uma avaliação mais detalhada do ambiente de trabalho de auxiliares que trabalham em turnos de 12 horas, seguidas de 36 horas de descanso, tanto no período diurno, como no período noturno, em busca de fatores que podem contribuir para o envelhecimento precoce. 


\section{Objetivo}

Este estudo teve como objetivo geral avaliar as condições do ambiente de trabalho de auxiliares de enfermagem do setor de ortopedia de um hospital público de São Paulo, como um complemento ao trabalho de Gonçalves et al. (2001).

Os objetivos específicos foram: 1) Avaliar as condições de trabalho em cinco setores do hospital: pronto-socorro, UTI, ala infantil, setor de lesados medulares e ala de adultos; 2) Comparar dados obtidos entre setores e segundo os turnos de trabalho (diurno: das $7 \mathrm{~h}$ às $19 \mathrm{~h}$ e noturno: das $19 \mathrm{~h}$ às $7 \mathrm{~h}$ ).

\section{Metodologia}

Os funcionários que participaram do trabalho anterior foram procurados e convidados a participar desta segunda etapa. Todos voluntários, preencheram um termo de consentimento, conforme Resolução da Comissão Nacional de Ética em Pesquisa, do Conselho Nacional de Saúde (CNS196/96).

A população observada neste estudo (12 pessoas) fazia parte de um grupo de 29 funcionários do hospital, todos auxiliares de enfermagem, que relataram dores ou lesões músculo-esqueléticas ao responderem o questionário do Índice de Capacidade para o Trabalho (Tuomi, Ilmarinen, Jahkola, Kataharinne \& Tulkki, 1997) em estudo anterior (Gonçalves et al., 2001). A idade média desses 29 trabalhadores avaliados era de 38,2 anos e tinham, em média, 6,3 anos de trabalho naquele hospital. Essas pessoas trabalhavam em turnos noturno ou diurno de 12 horas, seguidas de 36 horas de descanso. Não foram considerados neste estudo os trabalhadores em turnos de 6 horas diárias (matutinas e ou vespertinas): embora esses grupos trabalhassem parcialmente nos mesmos horários dos turnos de 12 horas diurnas não poderiam ser diretamente comparados, pois a freqüência e a distribuição das atividades de trabalho eram distintas.

As análises ergonômicas do trabalho foram realizadas em quatro setores do instituto: pronto-socorro, UTI, lesados medulares e ala dos adultos a partir das observações realizadas. Foram feitas 12 observações com duração de 12 horas cada: duas no período diurno (das $7 \mathrm{~h}$ às $19 \mathrm{~h}$ ) e duas no período noturno (das $19 \mathrm{~h}$ às $7 \mathrm{~h}$ ) no pronto-socorro; duas no período noturno e uma no período diurno no setor de lesados medulares; duas no período noturno e uma no período diurno no setor de adultos; uma no período noturno e uma no período diurno na UTI.

A ala infantil e o centro cirúrgico não foram observados devido à dificuldade de circulação de pessoas não autorizadas no centro cirúrgico e à reforma que estava ocorrendo na ala infantil.

O método utilizado neste estudo para avaliação de estressores ambientais e organizacionais no trabalho foi a Análise Ergonômica do Trabalho (AET) de Rohmert e Landau (1983). Esse método consiste em observações sistemáticas dos postos de trabalho. Permite a avaliação detalhada a partir da observação e do preenchimento, por um observador treinado, de 216 quesitos referentes aos seguintes campos: objetos de trabalho (homens, animais, plantas e materiais), equipamentos de trabalho, ambiente de trabalho (ambiente físico, organizacional e social, inclusive princípios e métodos de remuneração), análise das tarefas e demandas do trabalho (como exigências na percepção, nas tomadas de decisões e respostas às demandas). Algumas variáveis de natureza psicossocial - tais como, exigências excessivas de produtividade, pressões da hierarquia, falta de controle no trabalho e de apoio 
de colegas e de supervisores -, que podem levar ao aparecimento de doenças relacionadas ao trabalho e à incapacidade funcional precoce, não foram avaliadas neste estudo. Isso se deve à escolha da metodologia da Análise Ergonômica do Trabalho, que prioriza a avaliação dos aspectos ambientais e de certos aspectos organizacionais citados anteriormente. A AET, um método largamente utilizado por sua objetividade e sua abrangência, é o instrumento de escolha dos pesquisadores que avaliam o envelhecimento funcional precoce decorrente de más condições de trabalho e de vida (Ilmarinen, 1991).

\title{
Resultados da análise ergonômica do trabalho
}

\section{Caracterização do local de trabalho}

\author{
a) Pronto-socorro
}

A área total do pronto-socorro é de aproximadamente $400 \mathrm{~m}^{2}$ e é composta por posto de enfermagem, salas para atendimento de pacientes, sala de raio $X$, salas para internação de pacientes, banheiros, sala dos médicos e sala do enfermeiro chefe.

O pronto-socorro é um dos setores mais movimentados em comparação com os outros, tanto de dia, como à noite. Isso se deve ao fato de se tratar de um setor de emergências em que poucos pacientes ficam internados.

O posto de enfermagem é o lugar onde ficam os prontuários, o telefone, os medicamentos, alguns materiais de uso dos auxiliares, enfermeiros e médicos. Possui também um terminal de computador de uso dos funcionários para a busca de resultados de exames de pacientes ou dos próprios funcionários. A sala tem um balcão e duas cadeiras: as cadeiras não são ajustáveis, não têm apoio para os pés, não têm apoio para os braços; o balcão também não é ajustável e não tem apoio para os pés. $\mathrm{O}$ posto de enfermagem tem cerca de $12 \mathrm{~m}^{2}$, então, os auxiliares ficam pouco tempo dentro do posto de enfermagem durante o dia devido ao grande número de funcionários no plantão diurno e ao espaço reduzido da sala. Em geral, os enfermeiros ocupam mais a sala durante o dia. Já à noite, com o número reduzido de auxiliares de enfermagem de plantão e com apenas um enfermeiro chefe para todo o hospital, o posto de enfermagem é mais utilizado pelos auxiliares. Em geral, cerca de 5 funcionários trabalham de manhã, 4 à tarde e 2 à noite. No período da manhã, há maior necessidade de funcionários devido ao banho dos pacientes, o que não ocorre nos outros períodos. Trabalham cerca de 30 pessoas ou mais no setor de pronto-socorro (incluindo médicos, enfermeiros, auxiliares, técnicos de raio X, fisioterapeutas, nutricionistas, funcionários da limpeza etc.). Em geral, os auxiliares trabalham sozinhos ou em duplas em cada sala de atendimento aos pacientes. Muitas vezes têm de esperar os médicos fazerem a visita aos pacientes para começar ou dar continuidade ao seu trabalho, o que atrasa o andamento de suas atividades diárias.

b) Lesados medulares

A área total do setor gira em torno de $700 \mathrm{~m}^{2}$ e conta com 46 leitos. O setor de lesados medulares passou por uma reforma recente, a qual possibilitou que as portas dos quartos fechassem, o que melhorou o isolamento dos pacientes infectados. No entanto, como as portas dos quartos ficam fechadas e as janelas estão dispostas apenas nos quartos, o 
corredor de circulação não é muito ventilado. $O$ corredor tem iluminação baixa, mas o posto de enfermagem e os quartos, por serem locais em que os auxiliares passam mais tempo trabalhando, são bem iluminados. Após a reforma, os pacientes passaram a ter acesso à luz de cabeceira além de terem como chamar os auxiliares por um interfone que tem ligação direta com o posto de enfermagem. Isso facilita o trabalho dos auxiliares de enfermagem reduzindo a necessidade de andar várias vezes até os quartos, já que os pacientes têm condições de dizer pelo interfone o que desejam. Além disso, o interfone reduz o desgaste dos pacientes, que muitas vezes tinham que gritar para chamar os auxiliares, ou ficar esperando que eles aparecessem.

O andar tem uma copa para os funcionários; no entanto, a copa não tem janela, tem poucas cadeiras e cerca de $3 \mathrm{~m}^{2}$. Não há fogão, pia, forno de microondas nem sequer tomada para ligar um forno, caso houvesse um. Há também uma geladeira, uma mesa e um filtro.

No posto de enfermagem não há cadeiras suficientes para a quantidade de funcionários que trabalham no período diurno. Há um balcão, telefone, interfone, computador e, ao fundo, um balcão para o preparo de medicamentos, uma pia e um armário onde ficam guardados medicamentos e materiais.

Durante o dia trabalham cerca de 11 auxiliares de enfermagem, à tarde 4 e 3 à noite. Ficam internados cerca de 30 pacientes nesse setor.

\section{c) UTI}

A UTI tem aproximadamente $200 \mathrm{~m}^{2}$ incluindo semi-intensiva, intensiva, banheiro, dois postos de enfermagem (um para a semi e outro para a intensiva), sala de enfermagem, copa, sala para roupas sujas e armário e uma sala de macas. É uma área de acesso restrito, fechada por uma porta, onde as pessoas só podem entrar com autorização da enfermeira e vestidos com avental. A temperatura ambiente é sempre maior que a temperatura de fora do hospital, sendo que, algumas vezes, os auxiliares reclamaram de calor.

A iluminação nos postos de enfermagem é muito boa e em cima dos pacientes é mais baixa, por isso existe um foco de luz na cabeceira de cada paciente que só é acesa quando os auxiliares vão ministrar algum medicamento.

A quantidade de pacientes varia na UTI pelo fato dos pacientes não ficarem internados nesse setor por muito tempo, mas gira em torno de 6 a 8 pacientes por turno. $\mathrm{Na}$ UTI trabalham cerca de 6 auxiliares de enfermagem de manhã, 4 à tarde e 4 à noite, além de uma enfermeira durante o dia e outra à noite. Esse é o único setor que tem uma enfermeira que permanece durante toda a noite.

\section{d) Ala dos adultos}

A ala dos adultos tem a mesma área que a ala dos lesados medulares e também já passou pela reforma. A ala de adultos interna cerca de 35 pacientes para aproximadamente 13 auxiliares.

Assim como no setor de lesados medulares, os funcionários do setor de adultos não têm onde sentar e a copa é pequena, sem cadeiras suficientes, sem infra-estrutura. $\mathrm{O}$ setor compartilha dos mesmos problemas de ventilação por causa das portas dos quartos fechados, do mesmo modo como acontece no setor de lesados medulares. 


\section{Caracterização geral do trabalho dos auxiliares de enfermagem}

a) Divisão de trabalho

O trabalho do auxiliar de enfermagem é feito, em grande parte, individualmente. $\mathrm{O}$ enfermeiro chefe faz a divisão dos pacientes entre os membros da equipe e cada auxiliar fica responsável por um conjunto de pacientes durante todo o plantão. Às vezes ocorre, durante plantões de 12 horas no período diurno, a troca de funções ou de pacientes após o almoço. Isso tem como finalidade permitir que os auxiliares que ficaram com casos graves revezem com seus colegas que estavam com casos menos severos. Essas decisões são tomadas pelo enfermeiro encarregado do setor. Em algumas situações, como no banho de pacientes muito debilitados, os auxiliares pedem ajuda aos colegas de trabalho para conseguirem terminar suas tarefas sem atrasar outras e sem prejudicar os pacientes. As tarefas dos auxiliares são as mesmas, no entanto, há diferença entre os pacientes o que torna o trabalho dos auxiliares que cuidam dos casos graves mais pesado e difícil, mais trabalhoso. Sendo assim, o rodízio dos auxiliares entre os quartos nos diferentes turnos evita que um mesmo auxiliar trabalhe sempre com o mesmo tipo de paciente.

Apesar de haver uma ordem ou uma seqüência pré-estabelecida nas atividades, os auxiliares de enfermagem têm uma certa liberdade para realizar as tarefas que thes são confiadas. Assim, por exemplo, podem preparar logo no início do expediente toda a medicação que será administrada ou deixar para prepará-la um pouco antes do horário de seu uso.

Os auxiliares não têm subordinados para monitorar, no entanto, seu trabalho é supervisionado pelos enfermeiros, especialmente durante o dia, pois há um maior número de enfermeiros no período diurno (cerca de 1 ou 2 enfermeiros por setor) e apenas um para todo o instituto no período noturno, com exceção da UTI que tem um enfermeiro só para o setor durante a noite. No caso de entrada de novos colegas, os auxiliares de enfermagem se ajudam, resolvendo dúvidas uns dos outros ou até mesmo auxiliando diretamente no trabalho do colega.

O auxiliar é responsável pelo paciente de quem está cuidando, por isso só administra medicamentos prescritos, não pode tomar decisões sem consultar um enfermeiro ou um médico, para evitar erros ou acidentes. A monitoração do paciente é de responsabilidade do auxiliar de enfermagem, além de informar os médicos e enfermeiros caso haja alguma alteração significante em seu estado de saúde.

O cuidado com os equipamentos, instrumentos utilizados e materiais também faz parte da função dos auxiliares de enfermagem, devendo informar um superior caso haja algum estrago ou acidente. Como os auxiliares têm contato direto com os pacientes e por mais tempo, acabam sendo, na maioria das vezes, os responsáveis pela imagem do atendimento e pela reputação do hospital.

Tendo em vista todas essas responsabilidades e levando-se em conta todo o trabalho designado aos auxiliares de enfermagem, muitos conflitos são gerados por falta de comunicação ou mal-entendidos entre colegas, enfermeiros, médicos. Esse é um dos motivos pelos quais os prontuários devem estar sempre atualizados, para que a comunicação entre outros membros da equipe se dê de forma a facilitar o trabalho de todos.

b) Tempo gasto para realizar atividades de natureza física e mental

As atividades dos auxiliares de enfermagem são basicamente as mesmas em todos os setores do instituto: cuidados com pacientes, preparo de medicamentos, movimentação entre 
os quartos dos pacientes e outros setores, anotação e leitura de prontuários. No entanto, há algumas diferenças nos cuidados com paciente, dependendo do setor e do tipo de paciente (por exemplo: pacientes geriátricos, crianças ou lesados medulares).

As atividades observadas foram classificadas em "atividades que exigem predominantemente trabalho físico" e "atividades que exigem predominantemente trabalho mental". As atividades que exigem predominantemente trabalho mental do auxiliar de enfermagem são: "conversar com colegas, enfermeiros, médicos", "preparar medicamentos", "ler ou escrever prontuários". As atividades que exigem predominantemente trabalho físico dos auxiliares de enfermagem são: "cuidados com pacientes em geral" (como dar banhos, medicar pacientes, fazer curativos etc.), "movimentar-se entre quartos e outros setores", "manutenção de equipamentos" (como pegar, lavar, empurrar carrinhos etc.), "pegar materiais" (tais como lençóis, roupas sujas etc.). A Figura 1 apresenta a distribuição do tempo gasto nestas atividades durante o período diurno.

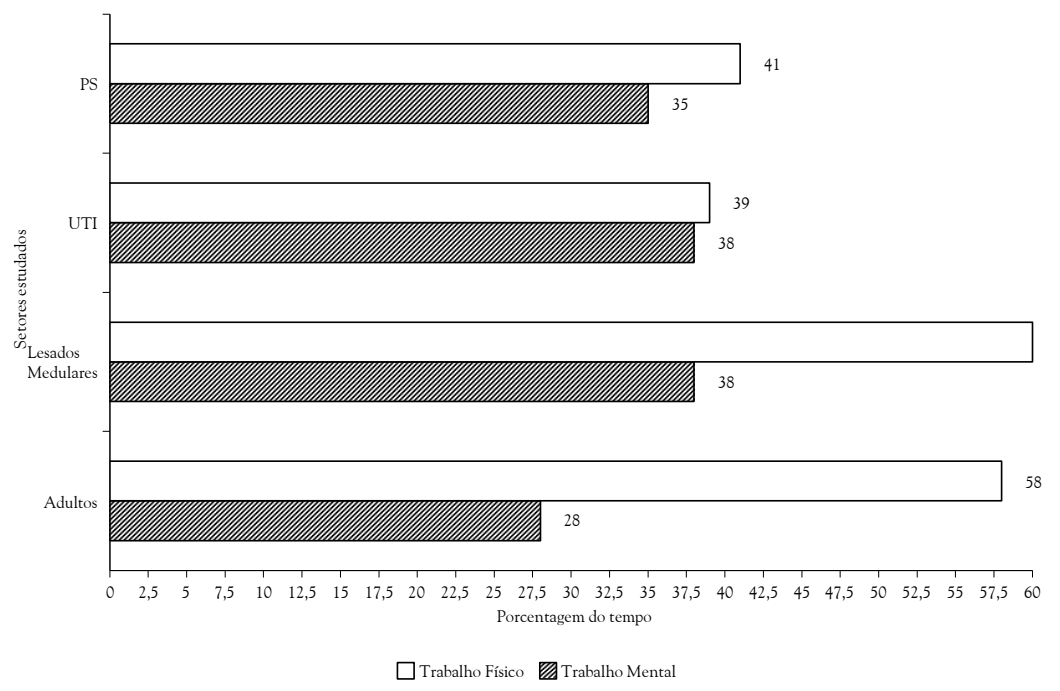

Figura 1: Porcentagem do tempo gasto pelos auxiliares de enfermagem em atividades que exigem predominantemente trabalho mental ou físico nos diferentes setores estudados de um instituto de ortopedia no período diurno (das 7h às 19h). Hospital público, São Paulo, 2001.

Essa figura mostra que, em todos os setores estudados no período diurno, as atividades que exigem dos auxiliares de enfermagem trabalho predominantemente físico ocupam maior porcentagem do tempo total do plantão de 12 horas (entre 30 e $60 \%$ do tempo) comparadas com as demais atividades (em torno de 30\% do tempo). No entanto, a diferença de porcentagem de tempo tomada pelas atividades predominantemente mentais e pelas predominantemente físicas diminui nos setores da UTI e do pronto-socorro. Isso mostra que tais setores exigem uma maior concentração nas atividades realizadas pelos auxiliares de enfermagem, por lidarem com casos mais graves e com pacientes sob risco de vida. Além disso, na UTI, há uma quantidade maior de aparelhos aos quais os pacientes ficam ligados; cada aparelho desses emite diferentes sons, aos quais os auxiliares também precisam estar atentos durante todo o plantão.

Os setores de lesados medulares e a ala de adultos têm mais pacientes que o prontosocorro e a UTI. Além disso, no setor de lesados medulares, os pacientes não podem se mexer, o que exige um gasto maior de tempo nos cuidados com os pacientes (atividades de esforço predominantemente físico). Esse dado é também mostrado na Figura 1.

É importante ressaltar que, por falta de vagas no hospital, uma alteração foi feita 
recentemente no pronto-socorro, que passou a prestar serviços de enfermaria além dos cuidados de emergência. Sendo assim, os auxiliares de enfermagem do pronto-socorro foram divididos entre dois setores: alguns atendiam os pacientes que estavam internados no prontosocorro e outros, os pacientes que entravam no pronto-socorro durante o plantão. Essa divisão foi feita pelo enfermeiro chefe durante o dia e pelos próprios auxiliares à noite.

Os auxiliares que atendem os pacientes que entram no pronto-socorro durante o plantão, apesar de muitas vezes fazerem mais esforço físico por terem que ajudar o paciente a sair do carro ou colocá-lo na maca, têm uma quantidade de serviço variada, dependendo do movimento. Já quem atende os pacientes internados no pronto-socorro é responsável pela medicação prescrita em certos horários, além de medicação fora de hora (contra a dor) e eventuais chamados dos pacientes; quem trabalha no período diurno, além disso, também é responsável pelos banhos dos pacientes. Sendo assim, quem fica responsável pelos pacientes internados tem mais tarefas a serem cumpridas e essas, conseqüentemente, devem ser realizadas num ritmo de trabalho mais intenso para que as medicações prescritas aos pacientes não se atrasem.

Os auxiliares de enfermagem de todos os setores têm de organizar os prontuários dos pacientes para que possam ser achados pelos colegas, enfermeiros, médicos, bem como atualizar os dados dos pacientes, tais como: temperatura, pressão, mencionar quais medicamentos foram ministrados em quais horários, anotar quantidade de urina eliminada pelo paciente, enfim, dados necessários para que os outros profissionais fiquem a par da situação do paciente. Portanto, as tarefas de anotação e leitura dos prontuários, bem como a organização desses papéis são muito importantes para o trabalho no hospital.

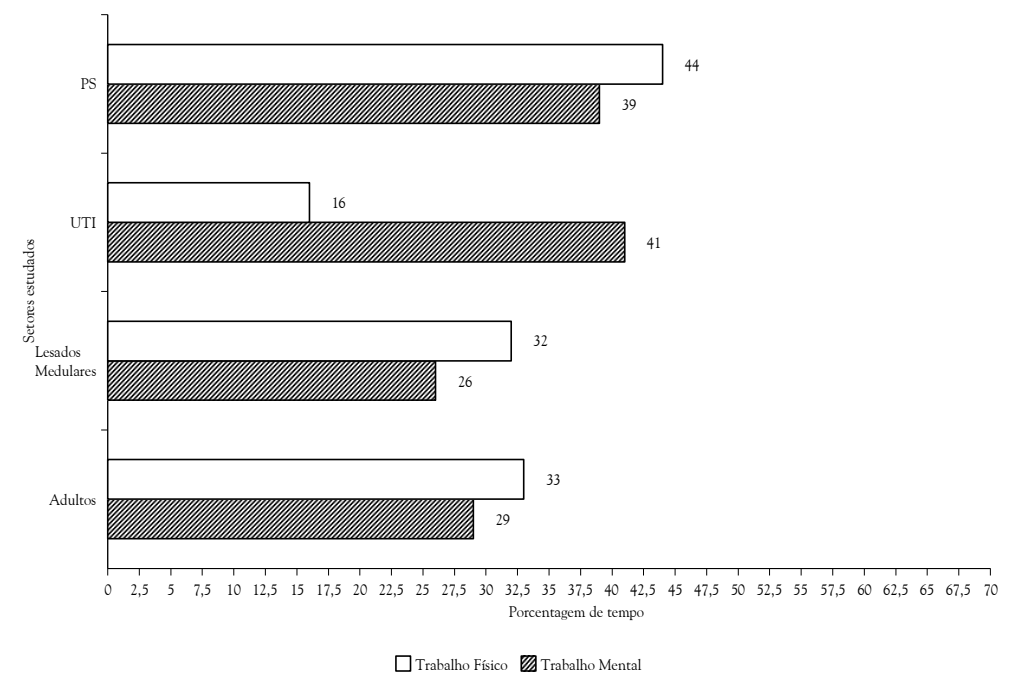

Figura 2: Porcentagem do tempo gasto pelos auxiliares de enfermagem em atividades que exigem predominantemente trabalho mental ou físico nos diferentes setores estudados de um instituto de ortopedia no período noturno (das 19h às 7h). Hospital Público, São Paulo, 2001.

A Figura 2 mostra que há uma diminuição considerável das atividades predominantemente físicas no setor de lesados medulares, na UTI e na ala dos adultos durante o período noturno. Essa diminuição se dá pela ausência de banhos no período da noite, atividade que consome muito tempo do plantão diurno, especialmente no setor de lesados medulares e na UTI, onde os pacientes estão impossibilitados de fazê-la sozinhos. As atividades de cuidados com pacientes à noite diminuem consideravelmente em todos os 
setores, exceto no pronto-socorro, onde o movimento é intenso tanto à noite, como durante o dia.

No entanto, as atividades que exigem trabalho predominantemente mental não têm muita alteração entre os dois períodos. Isso ocorre porque à noite também há comunicação entre os colegas, anotação e leitura de prontuários e preparo de medicamentos com uma freqüência aproximadamente igual à dos plantões diurnos. Nota-se também que a UTI tem um maior tempo gasto em atividades predominantemente mentais em comparação com os outros setores e muito maior que o tempo gasto em atividades predominantemente físicas. Isso se deve à quantidade de aparelhos aos quais os auxiliares devem estar alertas a noite toda e, também, ao espaço reduzido da UTI em relação aos outros setores, diminuindo a movimentação dos auxiliares de enfermagem.

\section{Recepção de informação}

Para fazer um julgamento das condições de saúde de um paciente, os auxiliares de enfermagem devem conhecer alguns padrões e reconhecer diferenças como, por exemplo, de cor ou de textura na urina ou no sangue, o aumento da área de alguma parte do corpo de um paciente (inchaços), distinguir os sons dos diferentes aparelhos, perceber variações nos sons de cada aparelho de monitoramento, saber de onde vêm esses sons, reconhecer variações de temperatura. Essas informações dependem da percepção do trabalhador e são importantes para o reconhecimento de alterações do estado de saúde dos pacientes, além de dados obtidos em certos aparelhos. Também é necessário que haja precisão na recepção de informação para que o julgamento a respeito do estado do paciente possa ser o mais próximo possível da realidade.

Muitas vezes o auxiliar não pode intervir assim que recebe a informação, pois não é autorizado a fazê-lo ou não tem conhecimentos necessários para essa intervenção. Nesses casos, tem de contatar o mais rápido possível alguém que possa intervir, já que seu poder de decisão sobre o paciente é pequeno.

O conhecimento de línguas estrangeiras às vezes é necessário para facilitar a recepção de informação, como, por exemplo, ler bulas ou ler a informação de algum aparelho. Há necessidade de um conhecimento mínimo dos termos técnicos, mas isso não é exigido pelo hospital. Muitas vezes os auxiliares sentiram dificuldade para entender algumas informações fornecidas por aparelhos (como, por exemplo, a bomba de difusão no caso de uma das observações feitas neste estudo) e tiveram de pedir auxílio aos colegas.

\section{Riscos de doenças ocupacionais}

O trabalho do auxiliar de enfermagem traz diversos riscos de doenças e acidentes ocupacionais que incluem: contato com bactérias, com materiais cortantes e contaminados, risco de quedas, levantamento de pesos (que pode acarretar problemas ósteomusculares), dentre outros. Por isso, são necessários alguns cuidados dos auxiliares tais como o uso de luvas, aventais e máscaras nos cuidados com pacientes infectados, utilização de instrumentos apropriados para suas atividades, uniforme apropriado etc. Além disso, é importante que o local de trabalho tenha uma boa infra-estrutura que proporcione boas condições de trabalho aos auxiliares.

No estudo anterior (Gonçalves et al., 2001), que antecedeu o presente estudo, verificou-se a presença de doenças osteomusculares em 52\% dos auxiliares de enfermagem entrevistados, dentre outras doenças. Esses dados mostram que a ocorrência de doenças possivelmente relacionadas ao trabalho é significativa. 


\section{Instrumentos utilizados}

São utilizados materiais para curativo como gases, ataduras, tesouras, esparadrapos, bem como fixadores, "comadres" e "papagaios" (para o paciente excretar quando não pode ir ao banheiro), seringas, dentre outros.

Os auxiliares utilizam dedos e mãos na maior parte de suas atividades. Alguns auxiliares de enfermagem reclamaram sentir dores no polegar da mão por fazerem movimentos repetitivos em seringas no preparo de medicamentos e na medicação dos pacientes. Já os pés não são tão utilizados para operar equipamentos ou controles, apenas para a locomoção, que é bastante freqüente em um hospital. Alguns equipamentos muito comuns e muito utilizados no trabalho dos auxiliares de enfermagem são termômetros, esfigmomanômetros (aparelhos para medição de pressão arterial), glicosímetros (utilizados na verificação da taxa de açúcar no sangue de diabéticos), dentre outros. Esses aparelhos são muito importantes para o trabalho do auxiliar de enfermagem, pois garantem a monitoração do estado do paciente para que haja sempre o controle sobre suas alterações físicas, possibilitando intervenções imediatas. Os instrumentos utilizados pelos auxiliares de enfermagem não variam entre os setores estudados.

\section{Influências do meio-ambiente de trabalho}

Todos os setores estudados têm boa iluminação durante o dia e a noite, principalmente os andares que já passaram pela reforma em andamento (lesados medulares, adultos e UTI), pois existem focos de luz que podem ser ligados nos quartos para melhorar a iluminação na hora dos cuidados com os pacientes. Não houve nenhuma reclamação em relação à iluminação por parte dos auxiliares observados. No entanto, os auxiliares reclamaram de calor com freqüência, tanto de noite, como de dia. Além da ventilação interrompida por biombos nas janelas, devido à reforma que está ocorrendo no hospital e às portas fechadas, a movimentação dos auxiliares é grande, o que pode ser um fator que contribui para a sensação de calor que relatam.

Em alguns momentos, os auxiliares reclamaram de odores desagradáveis que tomavam conta do corredor. Os odores desagradáveis são muito comuns e muitas vezes incomodam os auxiliares. Esses odores podem aparecer por diversos motivos: suor de funcionários e de pacientes, excretas de pacientes, entre outras coisas e, muitas vezes, permanecem no ar pela má ventilação dos andares.

Durante o dia há mais ruído do que durante a noite. Isso ocorre por diversos fatores: há maior movimentação de pacientes, familiares e funcionários. No período em que a pesquisa foi feita, diversos setores do instituto estavam sendo reformados, inclusive diante do pronto-socorro, o que gerou maior movimentação fora do prédio e o aumento do ruído devido às máquinas. Durante o dia, o telefone toca mais vezes devido à necessidade de comunicação entre setores e entre enfermeiros para conseguir vagas em enfermarias, no centro cirúrgico etc. O ruído muitas vezes incomoda, deixa os auxiliares mais agitados, eles, às vezes, precisam falar mais alto e isso é muito desgastante.

É comum que, durante o plantão, os auxiliares tenham de trabalhar em locais sujos (especialmente o chão, por exemplo, sujo de gesso) ou molhados (por estar sendo limpo pelos funcionários da limpeza). Especialmente quando trabalham com o chão molhado, correm risco de sofrer acidentes de trabalho como, por exemplo, escorregar.

$\mathrm{Na}$ maior parte do plantão, quando lidam com pacientes (cerca de 60\% ou mais do 
plantão de 12 horas), os auxiliares trabalham com luvas e eventualmente com máscaras e aventais de plástico: há risco de contaminação quando os pacientes estão com os curativos abertos.

\section{Os horários de trabalho}

Os auxiliares trabalham em quatro turnos diferentes: 6 horas no período matutino (todos os dias), 6 horas no período da tarde (todos os dias), 12 horas no período diurno seguidas de 36 horas de descanso e 12 horas no período noturno seguidas de 36 horas de descanso. Os turnos de trabalho são fixos e contínuos (incluindo fins de semana e feriados).

Os auxiliares que trabalham em plantões de 12 horas têm uma hora de pausa para almoço ou jantar, dependendo do turno; outras pausas para café, banheiro ou para fumar são informais, ou seja, os funcionários param quando querem ou quando podem.

\section{Posturas exigidas durante o trabalho dos auxiliares de enfermagem}

Foram observadas algumas diferenças entre os turnos de 12 horas de trabalho noturno e diurno no estudo anterior (Gonçalves et al., 2001) que foram confirmadas no presente estudo.

Os auxiliares que trabalham em turnos noturnos passam entre 30 e $60 \%$ do tempo sentados, enquanto os que trabalham em turnos diurnos passam entre 10 e $20 \%$ do tempo nessa posição. Atividades que exigem que o auxiliar se incline enquanto está sentado ocorrem em menos de $5 \%$ do tempo para o turno noturno e em até $15 \%$ do tempo para o turno diurno.

Os auxiliares que trabalham em turnos noturnos, passam de 40 a $70 \%$ do tempo em pé, enquanto os auxiliares que trabalham em turnos diurnos passam mais de $70 \%$ do tempo nessa posição. Atividades que exigem que os auxiliares fiquem ajoelhados ou agachados são menos freqüentes em ambos os turnos, tomando menos de $1 \%$ do turno de trabalho.

Os auxiliares que trabalham em turnos de 12 horas no período diurno permanecem grande parte do turno em pé, parados ou se locomovendo, quase o dobro do tempo que os auxiliares que trabalham em turnos noturnos. O pronto-socorro é o único setor que tem pouca diferença entre os dois turnos, pois é o único setor em que há entrada de pacientes tanto à noite, como de dia.

Os auxiliares que trabalham em turnos noturnos permanecem muito mais tempo sentados que os auxiliares que trabalham em turnos diurnos. A diferença é menor no prontosocorro, onde há movimentação grande tanto durante o dia, como à noite. O setor de lesados medulares foi o que teve a menor porcentagem de tempo em que os auxiliares permaneciam sentados durante o dia. Talvez isso se deva ao fato dos banhos serem mais demorados pela quantidade de pacientes e pelo fato dos pacientes não estarem possibilitados de ajudar no banho. Além disso, os auxiliares que trabalham no setor de lesados medulares são responsáveis pelo decúbito (virar os pacientes, mudá-los de posição a cada quatro horas). Essa é uma atividade que toma muito tempo dos auxiliares.

Os auxiliares que trabalham em turnos diurnos permanecem mais tempo inclinados que os auxiliares que trabalham em turnos noturnos. Isso se deve ao fato de os turnos diurnos, especialmente durante a manhã, serem responsáveis pelo banho, atividade que não aparece nos outros plantões. Além disso, nota-se que a UTI e o setor de lesados medulares têm uma porcentagem de tempo em que os auxiliares de enfermagem ficam inclinados à noite maior que nos demais setores. Isso se deve ao fato de que a UTI e o setor de lesados 
medulares terem pacientes muito debilitados, que não se movem e, assim, os auxiliares devem fazer o decúbito, atividade que não ocorre nos outros setores.

\section{A remuneração}

O salário dos auxiliares de enfermagem do hospital é calculado de acordo com negociação sindical anual. Todos os auxiliares ganham o mesmo valor, independentemente de tempo que trabalham na instituição, da idade ou do sexo. As possíveis variações que ocorrem no valor recebido pelo auxiliar devem-se ao período de trabalho (quem trabalha à noite ganha mais que quem trabalha durante o dia) e às horas trabalhadas (plantões e horas extras). O pagamento é feito mensalmente de acordo com as horas trabalhadas.

Para ser auxiliar de enfermagem é necessário fazer um curso técnico, que independe do grau de escolaridade da pessoa, contanto que saiba ler e escrever. Atualizações são sempre necessárias para que os funcionários estejam sempre informados das alterações em nomenclaturas de medicações ou em técnicas de intervenção. Muitos cursos de atualização são oferecidos pelo próprio hospital durante o horário de trabalho, do qual os auxiliares são dispensados por uma ou duas horas para poderem participar dos cursos.

\section{Discussão}

Este estudo mostrou algumas diferenças no trabalho dos auxiliares de enfermagem entre os setores e os turnos estudados. Apesar do cargo de auxiliar de enfermagem ser o mesmo e ter as mesmas atividades, o tempo nas atividades e a quantidade de atividades depende da quantidade de pacientes pelos quais os auxiliares se responsabilizam durante o plantão, do tipo de paciente (de acordo com o setor) e do turno (diurno ou noturno).

O trabalho do auxiliar de enfermagem exige tanto esforço físico como mental, no entanto, o trabalho físico é maior - especialmente no instituto de ortopedia, onde a maioria dos pacientes está impossibilitada de se mover. Foi possível notar que cada setor tem a sua peculiaridade. O pronto-socorro é caracterizado por uma movimentação constante, tanto durante o dia como à noite, o que torna os dois plantões muito parecidos.

Em todos os setores não há como desconsiderar o banho, atividade que requer tempo e esforço físico dos auxiliares, por ser uma atividade que exige que os auxiliares fiquem a maior parte do tempo inclinados. Essa diferença é significante quando comparados os dois turnos. Na UTI, assim como no setor de lesados medulares, há um grande número de pacientes internados que não podem se mover, o que dificulta ainda mais as atividades, principalmente o banho. Nesses andares, em geral, são necessários dois auxiliares para dar banho em cada paciente.

$\mathrm{Na}$ ala dos adultos os pacientes internados têm mais condições de ajudar em algumas tarefas, no entanto, há um grande número de pacientes geriátricos que também exigem um cuidado maior.

A UTI é uma enfermaria como todas as outras, mas requer atenção maior por parte dos auxiliares de enfermagem devido à gravidade do estado dos pacientes. Os auxiliares de enfermagem que trabalham na UTI têm de estar o tempo todo atentos aos sons dos aparelhos de monitoramento tanto à noite como durante o dia. É importante ressaltar que essa tarefa é 
mais difícil durante o dia devido aos ruídos de um maior número de pessoas trabalhando e da obra que está ocorrendo no hospital.

Apesar da reforma feita nos andares estudados, o ambiente de trabalho ainda tem alguns problemas: falta de cadeiras para todos os funcionários, a copa necessita de mais espaço e infra-estrutura, maior ventilação do corredor. Alguns auxiliares comentaram que a falta de conforto, de espaço e de infra-estrutura da copa seria para desestimular os funcionários a fazer suas pausas, para que o trabalho seja contínuo.

O número de auxiliares escalados por turno não varia de acordo com a quantidade de pacientes internados em cada setor. Esse fato faz com que muitas vezes os auxiliares fiquem sobrecarregados e, outras vezes, não tenham nada para fazer. É interessante observar que, por exemplo, no setor de adultos que tem, em média, 35 pacientes internados, no período da manhã cada auxiliar fica responsável pelos cuidados de 2 ou 3 pacientes. À tarde há uma diminuição dos auxiliares escalados, pois não há mais o banho, portanto, cada auxiliar tem, sob sua responsabilidade, os cuidados de aproximadamente 5 pacientes. Já no período noturno, quando são escalados no máximo 3 auxiliares, cada um fica responsável por aproximadamente 11 pacientes. Não há no instituto possibilidade de transferir auxiliares de um andar para o outro, com exceção da UTI e do setor de lesados medulares, que estão sob mesma chefia. $\mathrm{O}$ excesso de pacientes a serem cuidados pelos auxiliares no turno noturno é um problema nesse hospital. No caso de haver mais auxiliares que pacientes internados, os auxiliares não podem ser dispensados, por terem de cumprir horas mensais de trabalho, e, nesses casos, nem sequer têm um lugar para descansar, já que a copa e o posto de enfermagem não comportam muitas pessoas.

O pessoal da limpeza trabalha principalmente durante o dia, quando há mais serviço e mais funcionários transitando pelos andares. Em muitos momentos, os auxiliares correram risco de queda, ou até sofreram quedas, por entrarem em quartos que haviam sido encerados ou que estavam com o chão molhado. Como a empresa de limpeza é terceirizada, há muitos conflitos entre os auxiliares e o pessoal da limpeza, pois cada um tem de cumprir seu serviço. Além do risco de queda, a enceradeira faz muito barulho e, muitas vezes, tanto pacientes, como auxiliares reclamaram.

É de conhecimento na literatura científica que o turno noturno provoca alterações dos ritmos biológicos, inclusive gerando repercussões importantes à saúde.

Por um lado, as solicitações de trabalho predominantemente físico são mais freqüentes durante o turno diurno, podendo levar a maiores problemas músculo-esqueléticos. Por outro lado, o turno noturno traz outras dificuldades para o bom desenvolvimento das tarefas devido aos problemas de sono e a outros, gerados pela necessidade de vigília noturna. Foi observada uma sobrecarga de trabalho físico no período noturno, principalmente no setor de lesados medulares, dada a necessidade de fazer o decúbito dos pacientes e de haver um número muito reduzido de profissionais para cuidar desses pacientes.

\section{Conclusões}

As exigências posturais potencialmente mais prejudiciais ocorrem durante os turnos de trabalho no período diurno e com maior freqüência. Nesses turnos são mais freqüentes todas as atividades relacionadas aos cuidados com pacientes, incluindo o banho. No turno noturno as exigências posturais desfavoráveis são menos freqüentes, já que os pacientes necessitam de menos cuidados por estarem dormindo a maior parte do tempo. Embora o turno de trabalho noturno possa causar outros problemas de ordem biológica (desordem 
temporal interna dos ritmos biológicos), as exigências posturais são menores, o que pode ser um dos motivos da preferência de alguns trabalhadores por esse período de trabalho. No entanto, devido ao número reduzido de trabalhadores no período noturno, muitas vezes a carga de trabalho aumenta dependendo do número de pacientes, podendo trazer conseqüências negativas para a saúde dos funcionários.

Em decorrência das especificidades do tratamento dos pacientes, as cargas de trabalho físicas e mentais são distintas também entre os setores. $\mathrm{O}$ número de profissionais designados a cuidar dos pacientes não leva em conta as diferenças a serem desenvolvidas nos diferentes setores e turnos. Faltam instalações adequadas para o conforto dos funcionários durante as pausas.

O gerenciamento do corpo de enfermagem deveria levar em conta as particularidades dos setores e dos turnos de trabalho.

Foram observados durante as análises ergonômicas a existência de importantes estressores do trabalho, aqui especificados especialmente os de natureza física.

É uma tradição de décadas, entre trabalhadores da área de saúde, os esquemas de 12 horas de trabalho seguidas de 36 horas de descanso. Considerando os achados, cabe questionar a extensão dessas jornadas, bem como a organização do trabalho (pausas, folgas, ritmo de trabalho), em função das cargas de trabalho e do número de trabalhadores presentes para executá-las.

\begin{abstract}
Working conditions of practical nurses in an orthopedics and trauma institute of a public hospital in São Paulo, Brazil.

This study refers to a previous research related to aging and work (Gonçalves, 2001) conducted in a public hospital of São Paulo, Brazil. It was observed there is a decrease in working ability among practical nurses, due to working conditions and heavy job demands performed at work. Objectives: To present an evaluation of the practical nurses' working places during their daily 12-hour shifts, either during the day and at night. Working conditions of day and night shifts and wards of the hospital are described and compared. The observations were performed in various sections of the same hospital. The method used to collect the data was based on the ergonomic analysis technique by Rohmert and Landau (1983). Although day shifts demand considerable working load, night shifts can be equally exerting due to the reduced number of practical nurses during this period. It is of great importance to adapt the number of people on duty in each sector to the hospital according to work demands. This would help to overcome the hardships when healthcare personnel perform their routine tasks, as well as to promote better working conditions.
\end{abstract}

Keywords: shift workers, practical nurses, ergonomic work analysis, working conditions.

Endereços para contato com as autoras:

Mariana Brandão Lourenço Gonçalves: mariblg@yahoo.com,

Frida Marina Fischer: fmfische@usp.br 


\section{Referências bibliográficas}

Estryn-Behar, M. \& Bonnet, N. (1992). Le travail de nuit à l'hôpital. Quelques constats à mieux prendre en compte. Arch. mal. prof., 54 (8), 709-719.

Fischer, F. M. \& Bellusci, S. M. (2000). Work Ability Index: survey among health care shiftworkers of São Paulo, Brazil. In S. Hornberger, P. Knauth, G. Costa \& S. Folkard (Orgs.), Shiftwork in the $21^{\text {st }}$ Century (pp. 195-200). Frankfurt e Main: Peter Lang.

Fischer, F. M., Teixeira, L. R., Borges, F. N. S., Gonçalves, M. B. L. \& Ferreira, R. M. (2002). Percepção do Sono: duração, qualidade e alerta em profissionais da área de enfermagem. Cadernos de Saúde Pública, 18, 1261-1279.

Gonçalves, M. B. L., Fischer, F. M., Lombardi Jr., M. \& Ferreira, R. M. (2001). Work activities of practical nurses and risk factors for the development of musculoskeletal disorders. J. Human Ergol, 30, 369-374.

Ilmarinen, J. (1991). The aging worker. Scandinavian J Environ Health 17 (suppl).

Marziale, M. H. P. \& Carvalho, E. C. (1998). Condições ergonômicas do trabalho da equipe de enfermagem em unidade de internação de cardiologia. Rev latino-am. Enfermagem, 6 (1), 99-117.

Niedhammer, M. S., Lert, F. \& Marne, M. J. (1994). Effects of shiftwork on sleep among French nurses: a longitudinal study. J Occup Med., 6 (36), 667-674.

Rohmert, W. \& Landau, K. (1983). A new technique for job analysis. Londres e Nova Iorque: Taylor \& Francis.

Tuomi, K., Ilmarinen, J., Jahkola, A., Kataharinne, L. \& Tulkki, A. (1997). Índice de capacidade para o trabalho. Helsinki: Instituto de Saúde Ocupacional. [Traduzido e adaptado para língua portuguesa por Fischer F. M. et al., 1996].

Villatte, R., Gadbois, C., Bourne, J. P. \& Laurent, V. (1993) Pratiques de l'ergonomie à l’hôpital. Paris: InterEditions. 